\title{
Thermal Conductivity Modeling of Propylene Glycol - Based Nanofluid Using Artificial Neural Network
}

\author{
R. A. Mohamed, D. M. Habashy \\ Department of Physics, Faculty of Education, Ain Shams University, Heliopolis, Roxy, Cairo, Egypt \\ rashaaam@yahoo.com
}

Department of Physics, Faculty of Education, Ain Shams University, Heliopolis, Roxy, Cairo, Egypt

emad10@hotmail.com

\begin{abstract}
The article introduces artificial neural network model that simulates and predicts thermal conductivity and particle size of propylene glycol - based nanofluids containing $\mathrm{Al}_{2} \mathrm{O}_{3}$ and $\mathrm{TiO}_{2}$ nanoparticles in a temperature rang $20-80^{\circ} \mathrm{c}$. The experimental data indicated that the nanofluids have excellent stability over the temperature scale of interest and thermal conductivity enhancement for both nanofluid samples. The neural network system was trained on the available experimental data. The system was designed to find the optimal network that has the best training performance. The nonlinear equations which represent the relation between the inputs and output were obtained. The results of neural network model and the theoretical models of the proposed system were performed and compared with the experimental results. The neural network system appears to yield the best fit consistent with experimental data. The results of the paper demonstrate the ability of neural network model as an excellent computational tool in nanofluid field.
\end{abstract}

\section{KEYWORDS}

Artificial neural network, Modeling, Nanofluids, Thermal conductivity enhancement, Propylene glycol

\section{INTRODUCTION}

Cooling plays a vital role in high-tech applications such as chemical reactors, nuclear power, solar energy, electrical plants, transportation, manufacturing, automobile, energy supply, air conditioning, refrigeration systems, and microelectronics. Up to now, generally, conventional fluids such as water or some kinds of glycol with poor thermal conductivity are used as coolant. There are many practical problems and limitations with the old usage of conventional fluids in the cooling systems of any industry that improved needs for a new modern solution, the scientists have investigated a new concept called 'nanofluids'. [1].

Nanofluid was firstly introduced by Choi, [2] and it is defined as dispersion of nanoparticles in a base fluid such as water, ethylene glycol, propylene glycol or engine oil. The focus of recent researches have been on nanofluids because of their unique thermal properties and their potential applications in engineering and industry. The thermal properties, including thermal conductivity, viscosity, heat transfer coefficient, and critical heat flux, depend on several factors such as volume fraction, temperature, nanoparticle material, nanoparticle size, $\mathrm{pH}$, and the base fluid, etc. Recently, several authors have studied the thermal properties of nanofluids [38]. In the literature, several theories have been proposed to explain the reasons for the enhancement of heat conductivity of nanofluids. Different reasons are responsible for The enhancement of thermal conductivity; the increase in surface area and heat capacity of the fluid due to the presence of nanoparticles, the suspended nanoparticles themselves have higher thermal conductivity than that of the base fluid and the solid - liquid interface facilitates the transport of energy by the interaction and collision between the dispersed nanoparticles and the base fluid as reported by authors [9-16].

There are many theoretical models developed to predict the thermal conductivity of well-dispersed solidliquid mixtures by Maxwell (1981), Hamilton - Crosser (HC) (1962), Chen (2009), Bruggeman and Upper and lower Hashin -Shtrikman (HS) models. Maxwell model developed to predict the thermal conductivity of nanoparticle at low concentration. HC model is the adaptation of Maxwell model with the inclusion of 
empirical shape parameter for spherical and cylindrical medium shapes. The Chen model modifies the conventional form of Hamilton - Crosser model. The Bruggeman model is based on mean field approach. $[17,18]$.

Artificial neural network is a subdomain of artificial intelligence and has been utilized as a new computing technology in computer science fields. Artificial neural networks which are inspired from structure of human brain are recently being developed and advanced in terms of quality, quantity, and capability. Numbers of various techniques for neural calculations are growing in recent years [19-21].

A key limitation of that research is that designing a model based on artificial neural network to simulate and predict the dispersion stability and the thermal conductivity of propylene glycol based nanofluids. Also, we will compare artificial neural network trained results with that of classical theoretical models for the same experimental data. The major drawback of this approach is that the ability of our model, not only to simulate but also to predict results that are out the experimental data range with an excellent performance.

In the following sections, we will display the theoretical models, including Maxwell model, Hamilton - Crosser (HC) model, Chen model and Upper and lower Hashin-Shtrikman (HS) model. Then, we will review information on the artificial neural network, explain how we get the experimental data and finally we will discuss the results, comparing them with that of the theoretical models.

\section{THEORETICAL MODEL}

A number of theoretical models have been proposed for predicting the thermal conductivity of nanofluids [11].

\section{Maxwell Model}

Maxwell was the first scientist gives analytical expressions for effective conductivity of heterogeneous medium. This model may be applied to low-concentration liquid-solid suspensions with randomly dispersed, homogeneously sized, and non-interacting spherical particles. The thermal conductivity is given by:

$$
\frac{\mathrm{k}}{\mathrm{k}_{\mathrm{o}}}=\frac{\mathrm{k}_{\mathrm{p}}-2 \mathrm{k}_{\mathrm{o}}-2 \varphi\left(\mathrm{k}_{\mathrm{o}}-\mathrm{k}_{\mathrm{p}}\right)}{\mathrm{k}_{\mathrm{p}}+2 \mathrm{k}_{\mathrm{o}}+\varphi\left(\mathrm{k}_{\mathrm{o}}-\mathrm{k}_{\mathrm{p}}\right)}
$$

Where $\mathrm{k}_{1} \mathrm{k}_{\mathrm{o}}, \mathrm{k}_{\mathrm{p}}$ and $\varphi$ are the thermal conductivities of nanofluid, the thermal conductivities of the base fluid, the thermal conductivities of the nanoparticles and the volume fraction of nanoparticles in the mixture respectively.

\section{Hamilton - Crosser (HC) Model}

The Hamilton - Crosser $(\mathrm{HC})$ is an adapted model for considering the effect of particle shape and particle volume fraction on thermal conductivity of suspensions. They modified Maxwell model as shown in the following equation:

$$
\frac{\mathrm{k}}{\mathrm{k}_{\mathrm{o}}}=\frac{\mathrm{k}_{\mathrm{p}}-(\mathrm{n}-1) \mathrm{k}_{\mathrm{o}}-(\mathrm{n}-1) \varphi\left(\mathrm{k}_{\mathrm{o}}-\mathrm{k}_{\mathrm{p}}\right)}{\mathrm{k}_{\mathrm{p}}+(\mathrm{n}-1) \mathrm{k}_{\mathrm{o}}+\varphi\left(\mathrm{k}_{\mathrm{o}}-\mathrm{k}_{\mathrm{p}}\right)}
$$

Where $\mathrm{n}$ is the shape factor.

\section{Chen Model}


Modify the conventional form of Hamilton-Crosser model. It introduced the concept of the effective volume fraction of aggregates $\varphi_{\mathrm{a}}$ and replaced the term $\mathrm{k}_{\mathrm{p}}$ with $\mathrm{k}_{\mathrm{a}}$

$$
\frac{\mathrm{k}}{\mathrm{k}_{\mathrm{o}}}=\frac{\mathrm{k}_{\mathrm{a}}+2 \mathrm{k}_{\mathrm{o}}-2 \varphi_{\mathrm{a}}\left(\mathrm{k}_{\mathrm{o}}-\mathrm{k}_{\mathrm{a}}\right)}{\mathrm{k}_{\mathrm{a}}+2 \mathrm{k}_{\mathrm{o}}+\varphi_{\mathrm{a}}\left(\mathrm{k}_{\mathrm{o}}-\mathrm{k}_{\mathrm{a}}\right)}
$$

Where $\mathrm{k}_{\mathrm{a}}$ is to be determined from the Bruggeman model

$$
\frac{\mathrm{k}_{\mathrm{a}}}{\mathrm{k}_{\mathrm{o}}}=\frac{1}{4}\left\{\left(3 \varphi_{\mathrm{i}}-1\right) \frac{\mathrm{k}_{\mathrm{p}}}{\mathrm{k}_{\mathrm{o}}}+\left(3\left(1-\varphi_{\mathrm{i}}\right)-1\right)+\left[\left(\left(3 \varphi_{\mathrm{i}}-1\right) \frac{\mathrm{k}_{\mathrm{p}}}{\mathrm{k}_{\mathrm{o}}}+\left(3\left(1-\varphi_{\mathrm{i}}\right)-1\right)\right)^{2}+8 \frac{\mathrm{k}_{\mathrm{p}}}{\mathrm{k}_{\mathrm{o}}}\right]^{2}\right\}
$$

Where $\varphi_{i}$ is the solid volume fraction of combination of nanoparticles given by $\varphi_{i}=\left(r_{a} / r\right)^{D-3}$ where $r_{a}$ and $r$ are the radius of aggregates and single nanoparticles, respectively. $D$ is the fractal index, which equals 1.8 for nanofluids assuming diffusion with reduced aggregation.

\section{Upper and lower Hashin-Shtrikman (HS) model}

The upper HS bound relates to a nanocluster pattern with spherical inclusions of fluid regions while the lower HS bound assumes well - diffused nanoparticles in the base fluid.

$$
\mathrm{k}_{\mathrm{o}}\left(1+\frac{3 \varphi\left(\mathrm{k}_{\mathrm{p}}-\mathrm{k}_{\mathrm{o}}\right)}{3 \mathrm{k}_{\mathrm{o}}+(1-\varphi)\left(\mathrm{k}_{\mathrm{p}}-\mathrm{k}_{\mathrm{o}}\right)}\right) \leq \mathrm{k} \leq \mathrm{k}_{\mathrm{p}}\left(1-\frac{3(1-\varphi)\left(\mathrm{k}_{\mathrm{p}}-\mathrm{k}_{\mathrm{o}}\right)}{3 \mathrm{k}_{\mathrm{p}}-\varphi\left(\mathrm{k}_{\mathrm{p}}-\mathrm{k}_{\mathrm{o}}\right)}\right)
$$

\section{ARTIFICIAL NEURAL NETWORK (ANN)}

Artificial neural network (ANN) possesses large number of nodes working simultaneously to solve a certain problem. ANN consists of a group of neurons arranged into layers and connected through weight element known as synapses. An artificial neural network always contains one input layer, at least one hidden layer and one output layer. The number of nodes in the input layer relates to the number of parameters existing in the data set, while the number of nodes in the output layer depending on the solution domain of the problem. At each node, the weighted inputs are summed, threshold and then transferred to produce output for that node. These operations are shown in Fig.1. The activation functions transferred the node's output from input layer to output layer. They have different forms such as linear functions, threshold functions, sigmoid functions and bipolar sigmoid functions. The sigmoid function was selected as an activation function.

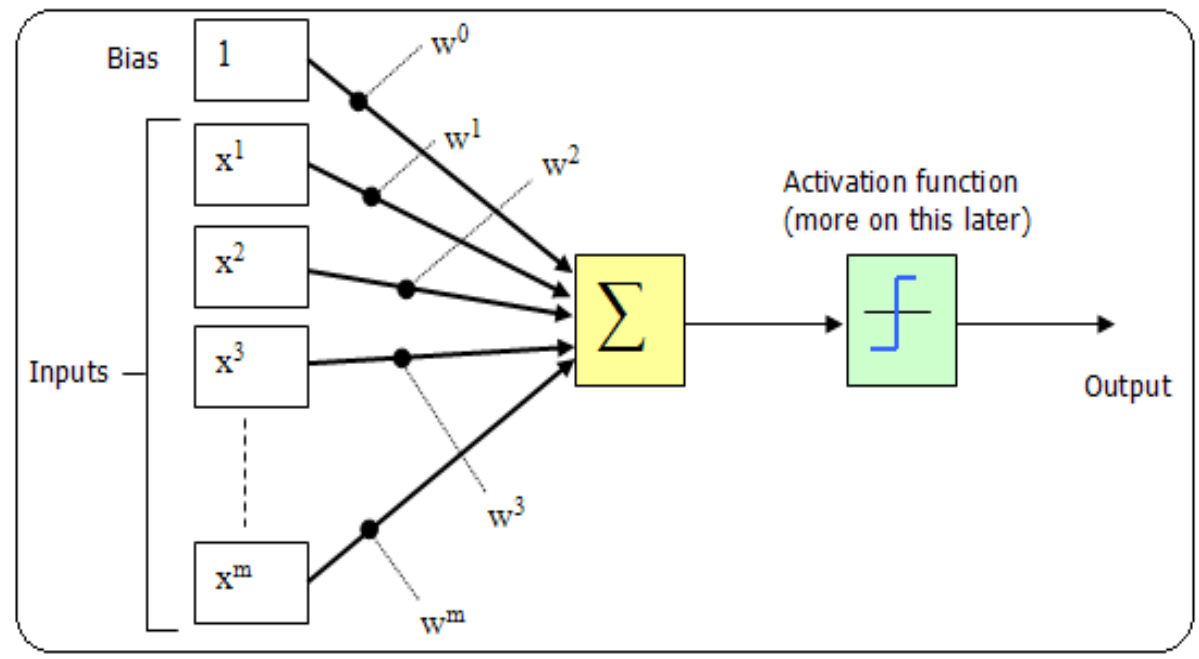

Fig 1: Operation at a node of neural network. 
The neural network determines the correlation between input and output variables by updating weights and biases. Values of these weight coefficients change during training the network. The activation function is defined by calculating the sum of the weighted inputs and the bias of each neuron to generate the neuron output. Modeling by using artificial neural network includes the three following steps: extracting required data for training the network, creating different structures by choosing number of hidden layers, number of neurons in each hidden layer and type of the activation function in order to obtain the optimal structure, and eventually, testing the neural network achieving the best fitting. [22-26].

\section{EXPERIMENTAL DATA}

Nanofluid samples containing propylene glycol (98\%), $\mathrm{TiO}_{2}$ and $\mathrm{Al}_{2} \mathrm{O}_{3}$ nanoparticles were prepared by the twostep method. The densities of $\mathrm{TiO}_{2}$ and $\mathrm{Al}_{2} \mathrm{O}_{3}$ nanoparticles were 4170 and $3970 \mathrm{~kg} / \mathrm{m}^{3}$ respectively. The concentration of nanoparticles was chosen to be 1,6 and 9 wt\%. Sonication was applied using a Digital Sonicator (Model S7OH by Elma, Germany) to decrease the size of clusters. The preparation of nanofluid samples was done without using any surfactant/pH modification showed excellent stability without any detectable sedimentation for several months.

Dispersion stability at different temperatures was evaluated by placing the nanofluid samples in an isothermal water bath and heating at $50^{\circ} \mathrm{C}$ for $80 \mathrm{hr}$, followed by $70^{\circ} \mathrm{C}$ and $80^{\circ} \mathrm{C}$ repeatedly for $40 \mathrm{hr}$ each. The particle size and $\mathrm{pH}$ were measured for each heating period at $25^{\circ} \mathrm{C}$. The thermal conductivity of the samples was measured with a Lambda Measuring System (PSLSystemtechnik GmbH, Germany) in a temperature range from 20 to $80^{\circ} \mathrm{C}$ soon after $16 \mathrm{hr}$ of sonication. The measuring of thermal conductivity was carried out depending on the transient heat-wire method, which decreases the convectional effects [10].

\section{THE PROPOSED ANN MODEL}

The artificial neural network model was trained using experimental data. They are randomly divided into two data sets which are training and testing data sets. We designed the neural network to model the particle size and the thermal conductivity enhancement as a function of temperature and concentration of nanoparticle. In order to detect the optimum network architecture, it is necessary to clarify the number of neurons in the hidden layer. Many structures of neural network were trained and the performances and correlation coefficient (R) were examined and recorded in Table 1. By training, it found that the created neural network configuration was formulated according to specification given in Table 2. The accuracy of the network was calculated by the mean squared error (MSE). Increasing number of neurons more than 5 has no-significant enhancement to the performance of the networks. It can be concluding that the best network with 5 neurons in one hidden layer gives minimum MSE as seen in Figure 2. The equations which describe the nonlinear relationship between inputs and outputs for all networks are given in Appendix A

\section{RESULTS AND DISCUSSION}

As can be shown in Figure 3 the thermal conductivity enhancement is illustrated versus temperature for PG $\mathrm{AL}_{2} \mathrm{O}_{3}$ and $\mathrm{PG}-\mathrm{TiO}_{2}$ nanofluid samples (1\%, $6 \%$ and $9 \mathrm{wt} \%$ ). A comparison between the experimental data and ANN trained results are depicted. The simulated results are in good harmony with the experimental data. The thermal conductivity enhancement for $\mathrm{PG}-\mathrm{AL}_{2} \mathrm{O}_{3}$ and $\mathrm{PG}-\mathrm{TiO}_{2}$ nanofluid samples $3 \%$ and $7 \%$ nanoparticle concentration are predicted using ANN model. A convenient behavior was obtained 
Table 1: ANN architecture

\begin{tabular}{ccccc}
\hline \multirow{2}{*}{$\begin{array}{c}\text { No. of } \\
\text { neurons }\end{array}$} & Mse & \multicolumn{3}{c}{$\mathrm{R}$} \\
\cline { 3 - 5 } & & Train & Test & All \\
\hline 1 & 0.05 & 0.9981 & 1 & 0.99842 \\
2 & 0.033175 & 0.99842 & 1 & 0.99869 \\
3 & 0.023143 & 0.99888 & 1 & 0.9992 \\
4 & 0.0178 & 0.9984 & 1 & 0.99841 \\
5 & 0.0008778 & 0.99997 & 1 & 0.99214 \\
\hline
\end{tabular}

Table 2: Optimal Neural network configuration.

\begin{tabular}{c|c|c|c|c|c|c}
\hline $\begin{array}{c}\text { No. of } \\
\text { neurons } \\
\text { in input } \\
\text { layer }\end{array}$ & $\begin{array}{c}\text { No. of } \\
\text { neurons } \\
\text { in hidden } \\
\text { layer }\end{array}$ & $\begin{array}{c}\text { No. of } \\
\text { neurons } \\
\text { in output } \\
\text { layer }\end{array}$ & $\begin{array}{c}\text { No. of } \\
\text { training } \\
\text { (epochs) }\end{array}$ & $\begin{array}{c}\text { Training } \\
\text { function }\end{array}$ & $\begin{array}{c}\text { Performance } \\
\text { function }\end{array}$ & $\begin{array}{c}\text { Activation } \\
\text { function }\end{array}$ \\
\hline 2 & 5 & 1 & 99 & $\begin{array}{c}\text { Bayesian } \\
\text { Regularization } \\
\text { trainbr) }\end{array}$ & $\begin{array}{c}\text { Mean } \\
\text { square error } \\
\text { (MSE) }\end{array}$ & $\begin{array}{c}\text { Tan-sigmoid } \\
\text { (tansig) }\end{array}$ \\
\hline
\end{tabular}

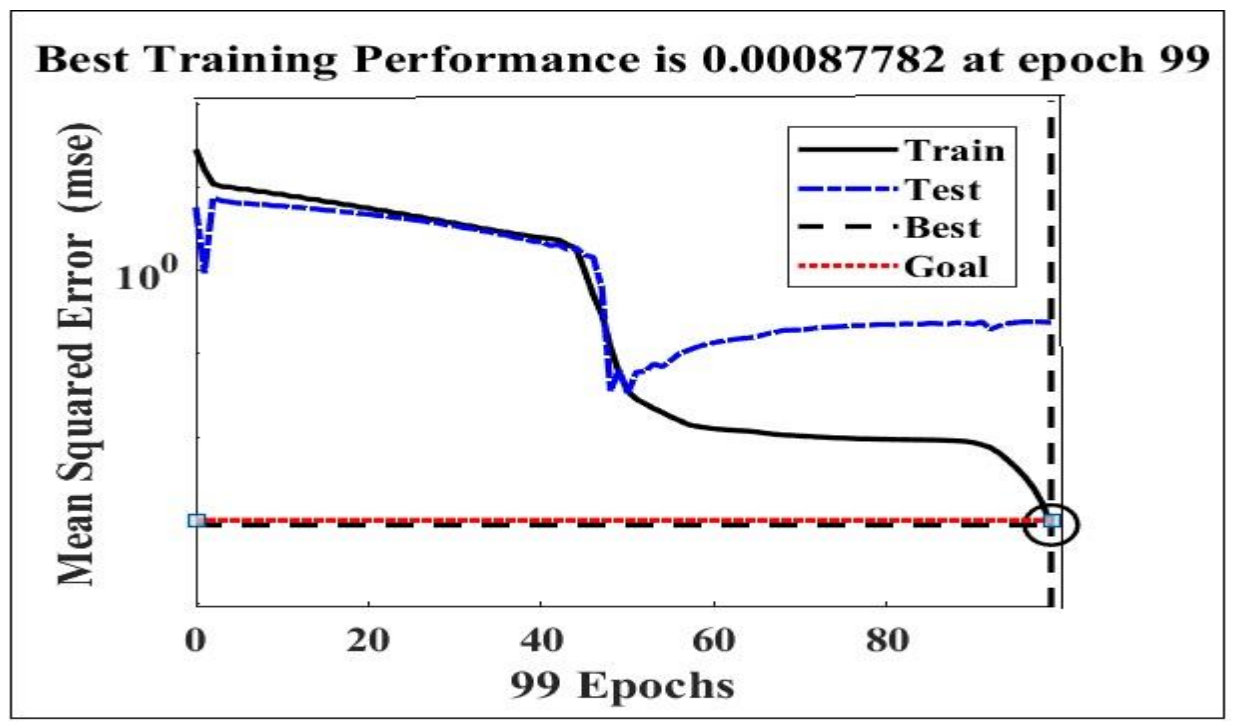

Fig 2: Training performance

Network correlation coefficients $(\mathrm{R})$ were obtained as shown in Figure 4. It was found to be 0.99214 and 0.9506 for $\mathrm{PG}-\mathrm{Al}_{2} \mathrm{O}_{3}$ and $\mathrm{PG}-\mathrm{TiO}_{2}$ nanofluid samples, respectively. The effect of temperature $\left({ }^{\circ} \mathrm{C}\right)$ on particle size $(\mathrm{nm})$ for different nanoparticle concentration $1 \%, 6 \%$ and $9 \mathrm{wt} \%$ of $\mathrm{PG}-\mathrm{Al}_{2} \mathrm{O}_{3}$ and PG- $\mathrm{TiO}_{2}$ nanofluid samples were shown in Figure 5(a) and (b), respectively. Experimental data are compared with the trained results based on ANN model. Also it found that the predicted results for $3 \%$ and $11 \%$ nanoparticle concentration thus obtained are compatible with the simulated results and experimental data. The regressions represented in Figure $6(\mathrm{a})$ and (b) indicate the closeness among the experimental data and the trained results, where the correlation coefficient $(R)$ are 0.98263 and 0.99173 , respectively. 
Consider Figure 7, which shows A comparison between the experimental data, the theoretical models (Maxwell model, Hamilton - Crosser ( $\mathrm{HC}$ ) model, Chen model and Upper and lower Hashin - Shtrikman (HS) model) and the proposed ANN model for PG $-\mathrm{AL}_{2} \mathrm{O}_{3}$ and $\mathrm{PG}-\mathrm{TiO}_{2}$ nanofluid samples. The theoretical models showed results matched the experimental data with high error percentage while The proposed ANN model provided to demonstrate excellent agreement with the experimental data with minimum error matches the performance goal $10^{-3}$ and correlation coefficient $(\mathrm{R})$ equal 0.94384 as presented in Figure 8 . It can be concluding that experimental data and results predicted by neural network have been compared to theoretical models. To verify this method, the experimental results is compared with ANN model outputs and it has been found that there is a very good agreement between them. Moreover, the model has a power to predict the thermal conductivity enhancement accurately. The ANN model was utilized to predict values were not given in training. As mentioned pervious the predicted results were found to be in a good fitting with experimental data. Furthermore, by generalization, the neural network model can be a helpful tool in predicting various properties of nanofluids.

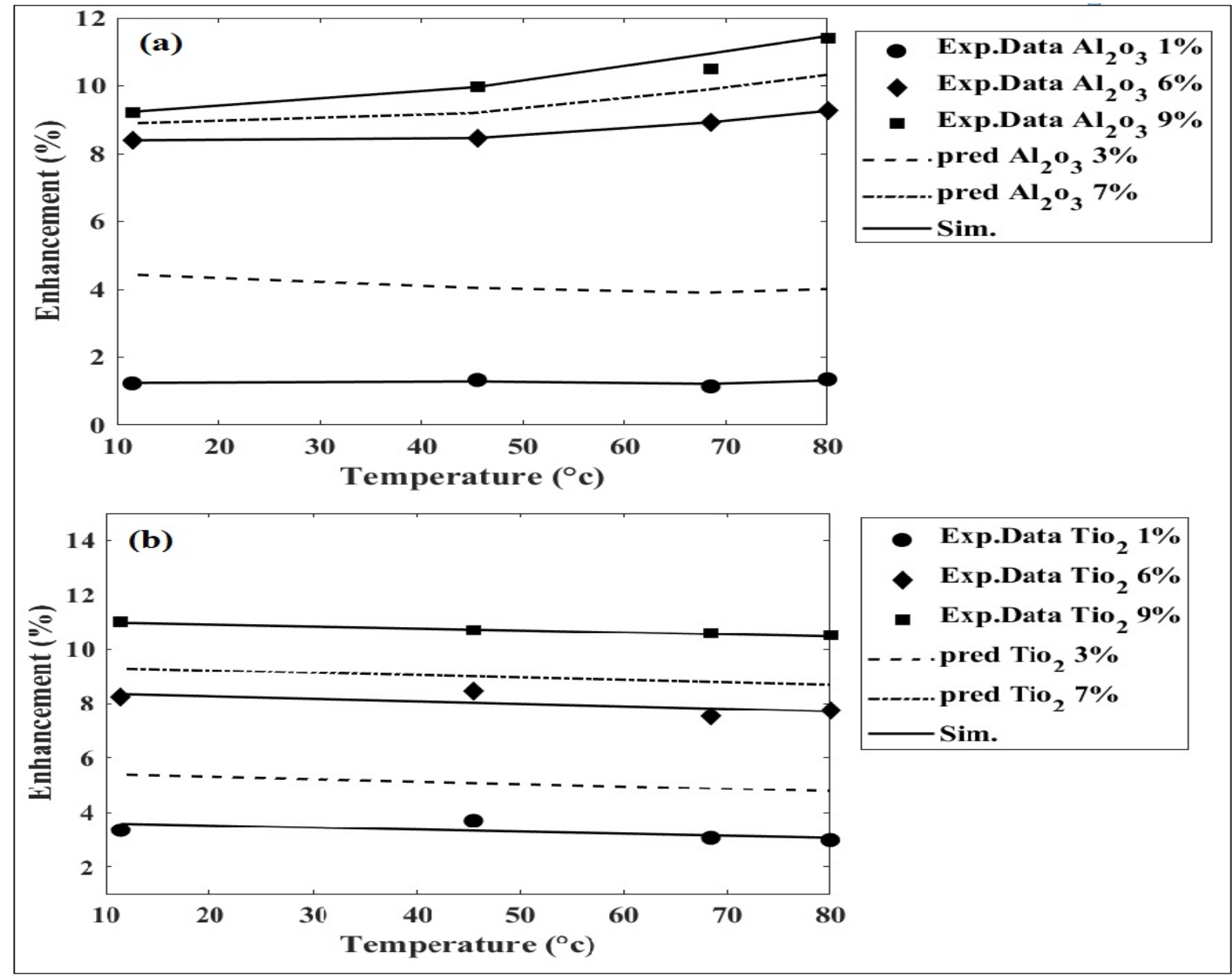

Fig 3(a) and (b): Illustrates the relation between thermal conductivity and temperature $\left({ }^{\circ} \mathrm{c}\right)$ enhancement (\%) at different nanoparticle concentration compared with the trained data using $A N N$ model for $P G-\mathrm{Al}_{2} \mathrm{O}_{3}$ and $P G-$ $\mathrm{TiO}_{2}$ nanofluid samples, respectively. 


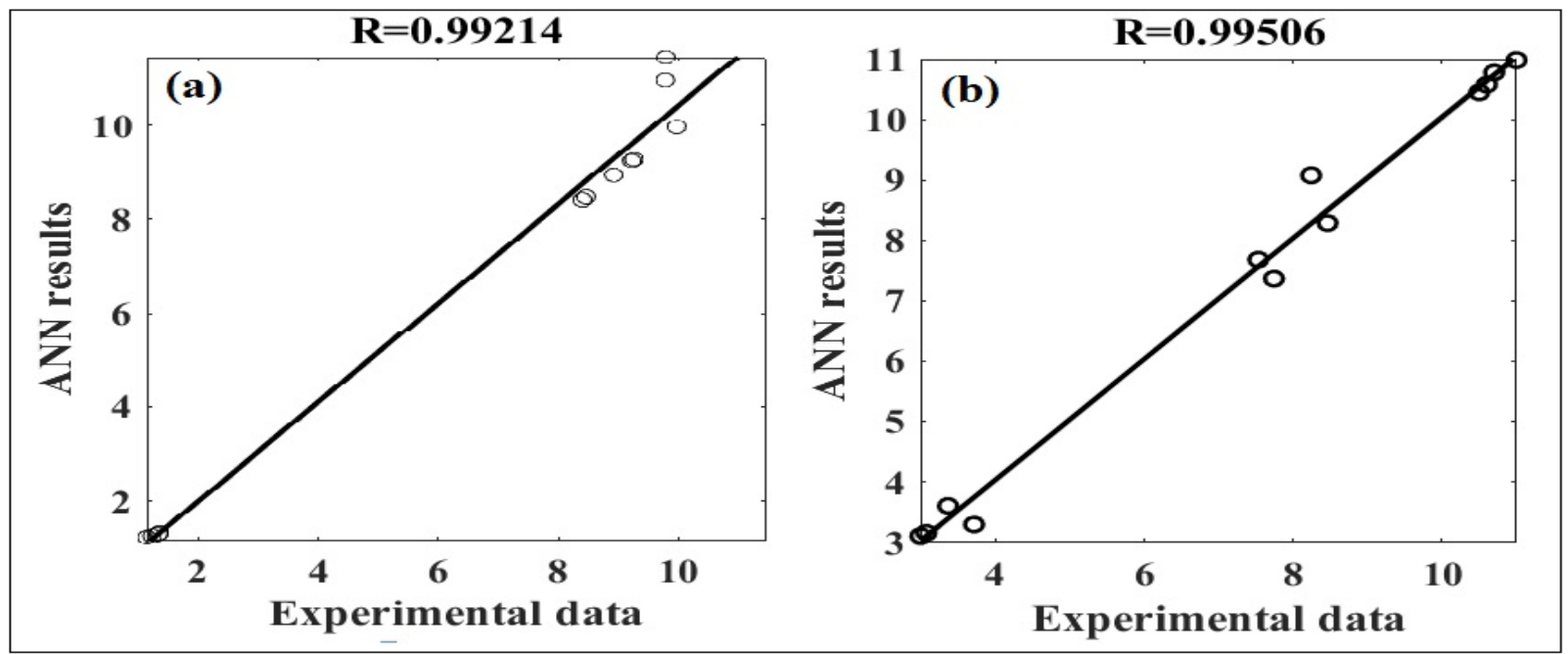

Fig 4(a) and (b): Modeling ability of the optimized ANN to simulate and predict the thermal conductivity enhancement of nanofluids for $\mathrm{PG}-\mathrm{Al}_{2} \mathrm{O}_{3}$ and $\mathrm{PG}-\mathrm{TiO}_{2}$ nanofluid samples, respectively.

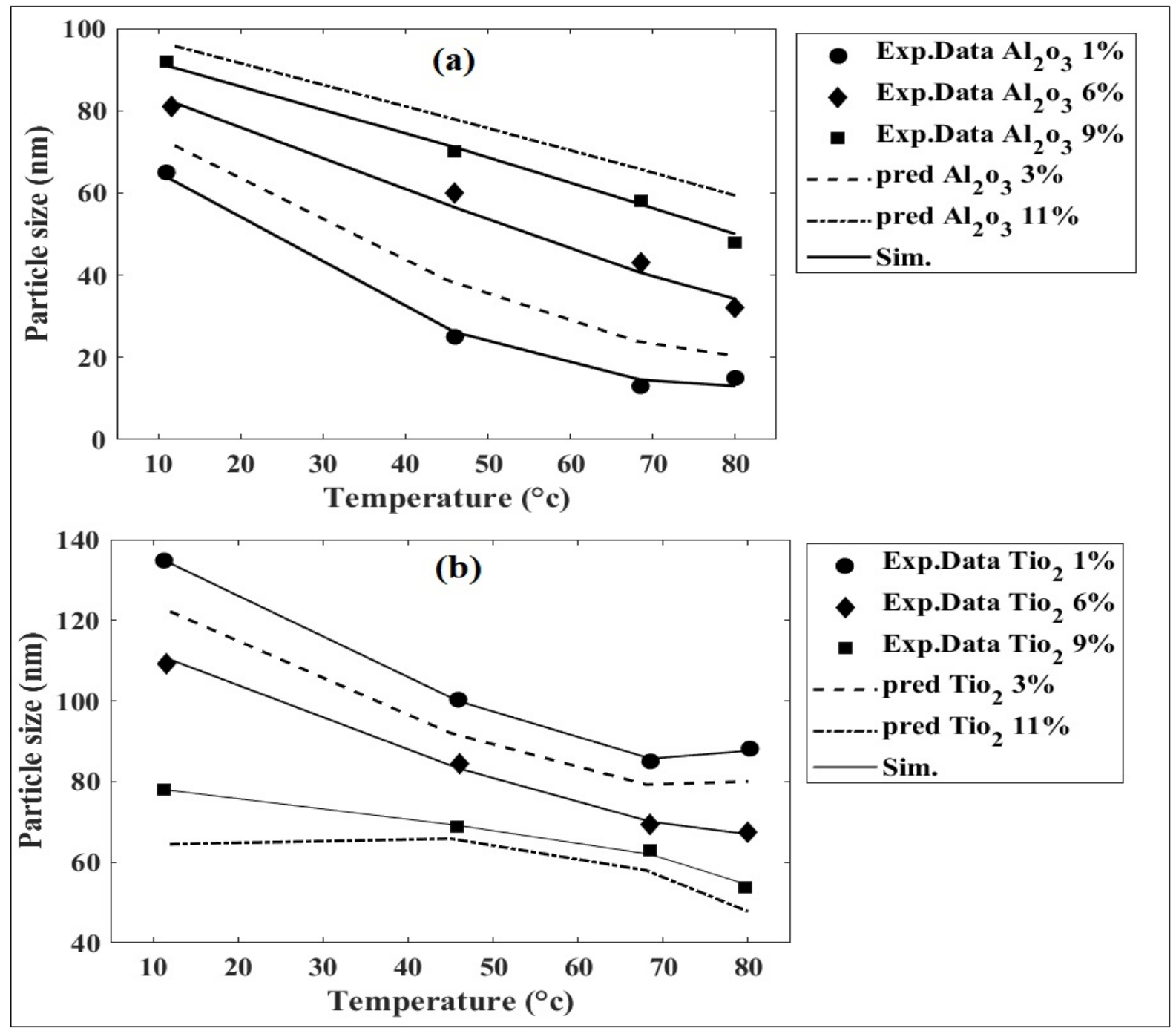

Fig 5(a) and (b): The training data set using ANN model for temperature $\left({ }^{\circ} \mathrm{c}\right)$ against particle size $(\mathrm{nm})$ at different concentration of $\mathrm{PG}-\mathrm{Al}_{2} \mathrm{O}_{3}$ and $\mathrm{PG}-\mathrm{TiO}_{2}$ nanofluid samples, respectively. 


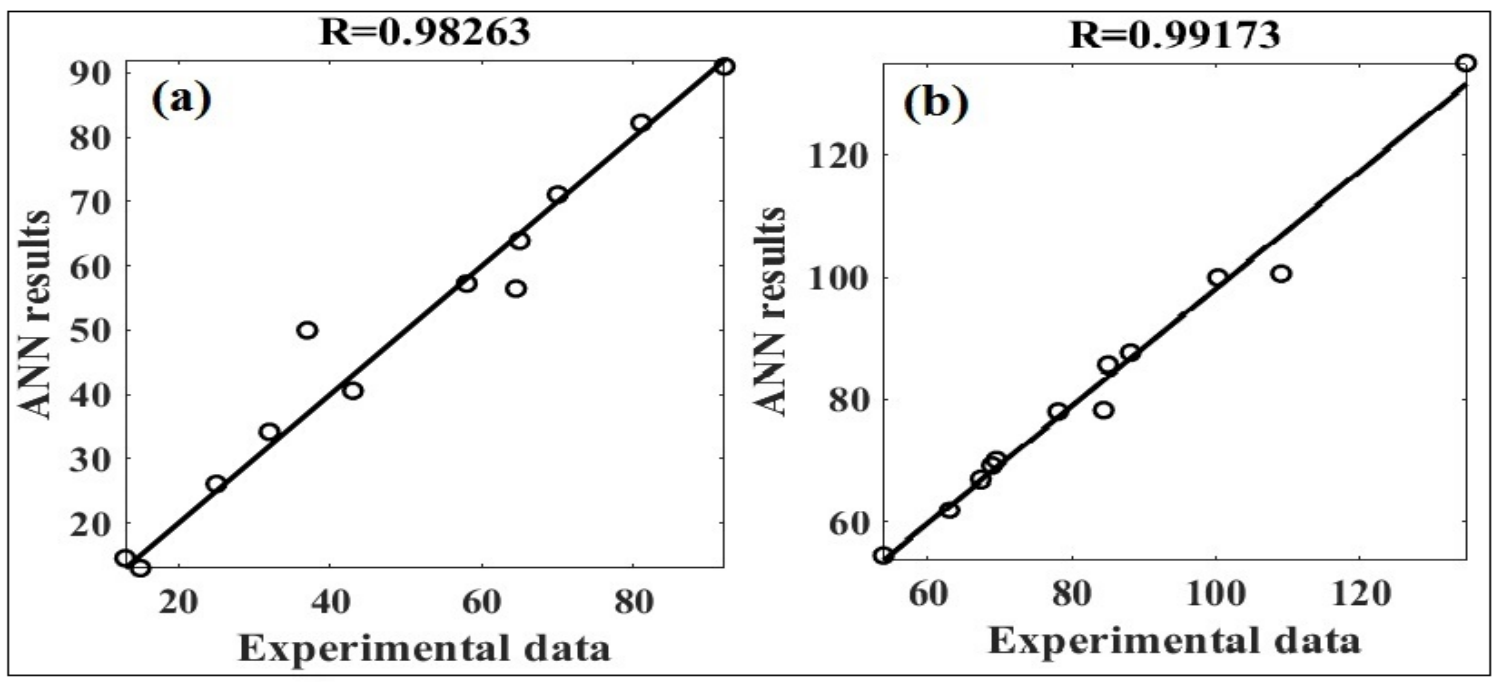

Fig 6(a) and (b): Regression plot between ANN results and experimental data for temperature $\left({ }^{\circ} \mathrm{c}\right)$ against particle size $(\mathrm{nm})$ at different concentration of $\mathrm{PG}-\mathrm{Al}_{2} \mathrm{O}_{3}$ and $\mathrm{PG}-\mathrm{TiO}_{2}$ nanofluid samples, respectively.

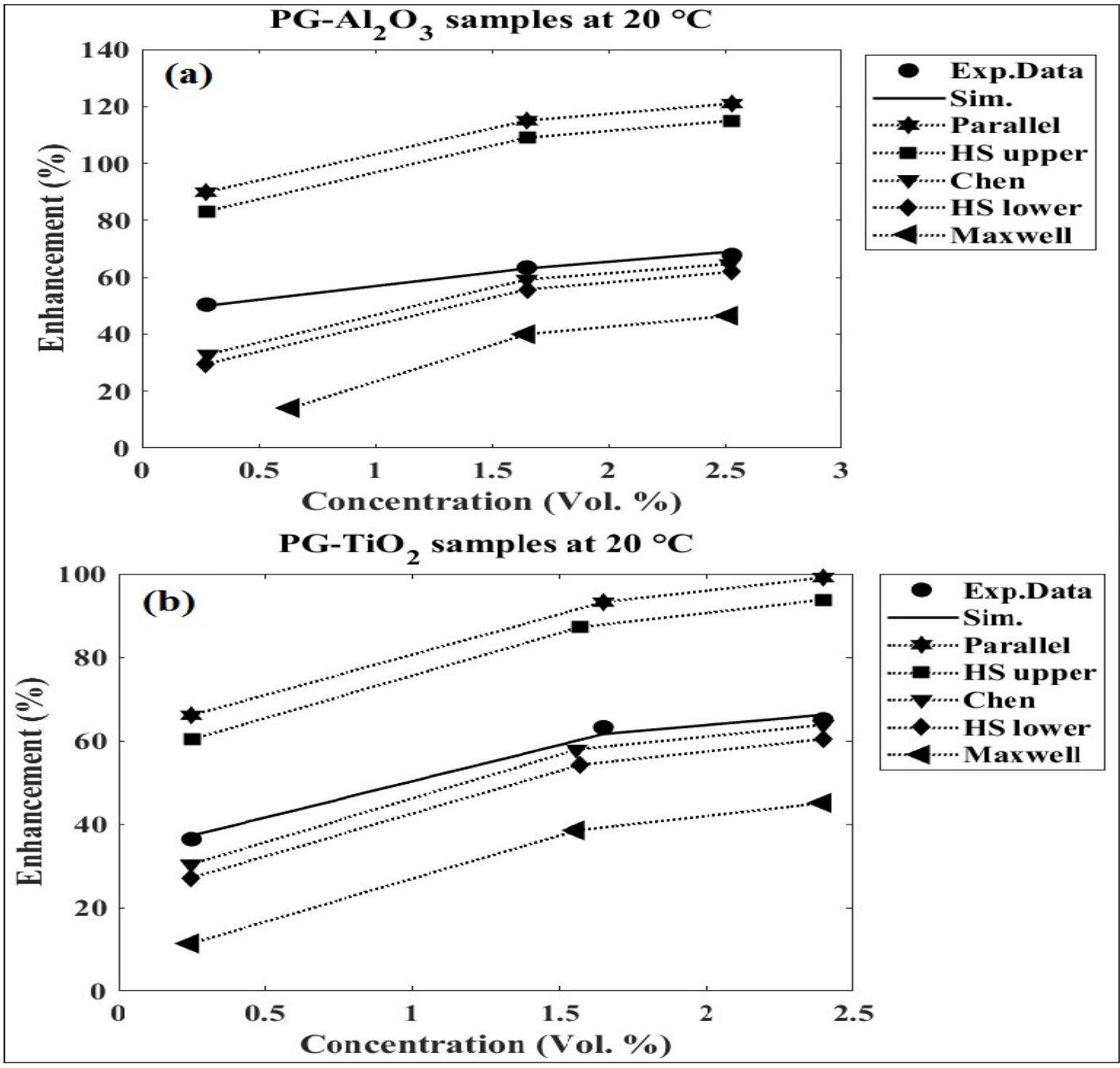

Fig 7: Comparison between experimental data, theoretical models and ANN model, showing the effect of concentration (Vol. \%) on the thermal conductivity enhancement (\%) for PG $-\mathrm{Al}_{2} \mathrm{O}_{3}$ and $\mathrm{PG}-\mathrm{TiO}_{2}$ nanofluid samples, respectively. 


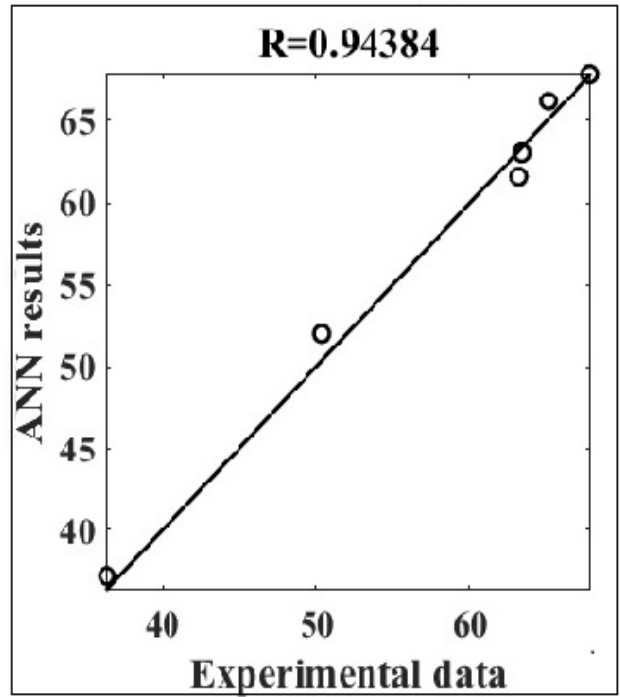

Fig 8: ANN results versus experimental data of thermal conductivity enhancement (\%) as a function of concentration of nanoparticles (Vol. \%) for PG $-\mathrm{Al}_{2} \mathrm{O}_{3}$ and $\mathrm{PG}-\mathrm{TiO}_{2}$ nanofluid samples, respectively.

\section{CONCLUSION}

The ANN network with Bayesian regularization training algorithm was used to train the experimental data. The configuration of the ANN model which has 5 neurons arranged in one hidden layer was found to be the best network and their outputs were in good agreement with the experimental data. The distribution of data points for ANN model almost similar and close to the actual experimental data with correlation coefficient (R) in range of 0.94 - 1.0. The optimal neural network has an ability to follow experimental data patterns with high accuracy. Moreover, the proposed model is capable of predicting results that was not used in the training session. The results of the ANN model for simulation and prediction are a significantly efficient and advanced over the traditional theoretical models. Finally, we conclude that the artificial neural network grows to be one of the significant branch in nanofluid studies.

\section{REFERENCES}

1. Bashirnezhad, K., Rashidi, M. M., Yang, Z., Bazri, S. and Yan., W. M. 2015. A comprehensive review of last experimental studies on thermal conductivity of nanofluids. J Therm. Anal. Calorim. 122, 863-884.

2. Choi., S. U. S. 1995. Enhancing Thermal Conductivity of Fluids with Nanoparticles in Developments and Applications of Non Newtonian flows. American Society of Mechanical Engineers. 23, 99-105.

3. Barbe's, B., Pa'ramo, R., Blanco, E., Pastoriza-Gallego, M. J., Piñeiro, M. M., Legido, J. L. and Casanova, C. 2013. Thermal conductivity and specific heat capacity measurements of $\mathrm{Al}_{2} \mathrm{O}_{3}$ nanofluids. J Therm. Anal. Calorim.11,1615-1625.

4. Chandrasekara, M., Sureshb, S. and Senthilkumara, T. 2012 Mechanisms proposed through experiments investigations on thermos-physical properties and forced convective heat transfer characteristics of various nanofluids. a review. Renew Sustain Energy Rev.16, 3917-38.

5. Gowda, R., Sun, H., Wang, P., Charmchi, M., Gao, F. and Gu., Z. 2010. Effects of particle surface charge, species, concentration, and dispersion method on the thermal conductivity of nanofluids. Adv. Mech. Eng. 2010, 1-10. 
6. Hemmat Esfe, M., Saedodin, S., Wongwises, S. and Toghraie., D. 2015. An experimental study on the effect of diameter on thermal conductivity and dynamic viscosity of $\mathrm{Fe} /$ water nanofluids. $J$ Therm Anal Calorim. 119, 1817-1824.

7. Hwang, Y. J., Ahn, Y. C., Shin, H. S., Lee, C. G., Kim, G. T. and Park, H. S. 2006. Investigation on characteristics of thermal conductivity enhancement of nanofluids. Curr. Appl. Phys. 6, 1068.

8. Mintsa, H. A., Roy, G., Nguyen, C. T. and Doucet, D.2009. New temperature dependent thermal conductivity data for water-based nanofluids. Int. J. Therm. Sci. 48, 363-71.

9. Aishwarya, V., Suganthi, K. S., Rajan, K. S. 2013. Transport properties of nano manganese ferritepropylene glycol dispersion (nanofluids): new observations and discussion. J. Nanopart. Res. 15, 1774-1788.

10. Palabiyik, I., Musina, Z., Witharana, S. and Ding., Y. 2011. Dispersion Stability and Thermal Conductivity of Propylene Glycol Based Nanofluids. J. Nanopart. Res. 13, 5049-5055.

11. Suganthi, K. S., Anusha, N. and Rajan, K. S. 2013. Low viscous ZnO-propylene glycol nanofluid: a potential coolant candidate. J. Nanopart Res. 15, 1986-1992.

12. Sun, T. and Teja, A. S. 2004. Density viscosity and thermal conductivity of aqueous solutions of propylene glycol, dipropylene glycol, and tripropylene glycol between $290 \mathrm{~K}$ and $460 \mathrm{~K}$. Journal of Chemical and Engineering Data. 49, 1311-1317.

13. Tillman, P. and Hill, J. M. 2007. Modelling the Thermal Conductivity of Nanofluids. IUTAM Symposium on Mechanical Behavior and Micro-Mechanics of Nanostructured Materials. 144, 105118.

14. White, S. B., Shih, A. J. and Pipe, P. K. 2011. Investigation of the electrical conductivity of propylene glycol-based ZnO nanofluids. Nanoscale Research Letters. 6, 346-351.

15. Xie, H., Yu, W., Li, Y. and Chen, L. 2011. Discussion on the thermal conductivity enhancement of nanofluids. Nanoscale Research Letters. 6, 124 - 136.

16. Yapici, K., Cakmak, Nese K., Naciye, I. and Uludag, Y. 2014. Rheological characterization of polyethylene glycol based $\mathrm{TiO}_{2}$ nanofluids. Korea-Australia Rheology Journal. 26, 355-363.

17. Kumar, P. M., Kumar, J., Tamilarasan, R., Sendhilnathan, S. and Suresh, S. 2015. Review on nanofluids theoretical thermal conductivity models. Engineering Journal. 19, 67-83.

18. Wang, X. and Mujumdar, A. S. 2008. A Review on nanofluids - Part I: Theoretical and Numerical investigations. Brazilian Journal of Chemical Engineering. $25613-630$.

19. David Kriesel. 2007. A Brief Introduction to Neural Networks.

20. Kumar, K., Mitra Thakur, G. S. 2012. Advanced Applications of Neural Networks and Artificial Intelligence: A Review. International Journal Information Technology and Computer Science. 6, 5768.

21. Peterson, C. and Rognvaldsson, T. 1991. An introduction to artificial neural network. CERN.1991,113-170.

22. El-Bakry, M. Y. 2003. Feed Forward Neural Networks Modeling for K-P Interactions. Chaos, Solitons and Fractals.18, 995-1000. 
23. El-Dahshan, E., Radi, A., El-Bakry and M. Y., El-Mashad, M. 2009. Artificial Neural Network Modeling in Heavy Ion Collisions. International Journal of Pure and applied Physics. 5, 1-14.

24. Michael Negnevitsky. 2005. Artificial Intelligence: A Guide to Intelligent System, Addison Wesley, England.

25. El-Bakry, Mostafa Y., Habashy, D. M. and El-Bakry., M. Y. 2014. Neural Network Model for Drag Coefficient and Nusselt Number of Square Prism Placed Inside a Wind Tunnel. International Journal of Scientific Engineering Research. 5,1411-1417.

26. El-Bakry, Mostafa Y., Habashy, D. M. and El-Bakry, M. Y. 2015. Effect of Particles on Flow Structures in Secondary Sedimentation Tanks Using Neural Network Model. International Journal of Scientific and Research. 6, 49-54.

\section{APPENDIX A:}

The equation which describes the nanoparticle size $(\mathrm{nm})$ and the thermal conductivity enhancement (\%) as a function of temperature for both nanofluid samples $\mathrm{PG}-\mathrm{TiO}_{2}$ and $\mathrm{PG}-\mathrm{AL}_{2} \mathrm{O}_{3}$ is given by:

The output $=$ Pureline $[$ net. tansig (net. LW $\{2,1\}$ tansig (net. IW $\{1,1\} A+$ net.b $\{1\})+$ net. $b\{2\})]$

Where

$A$ is the input

net. IW $\{1,1\}$ is linked weights between the input layer and first hidden layer,

net. LW $\{2, \quad 1\}$ is linked weights between first and output layer.

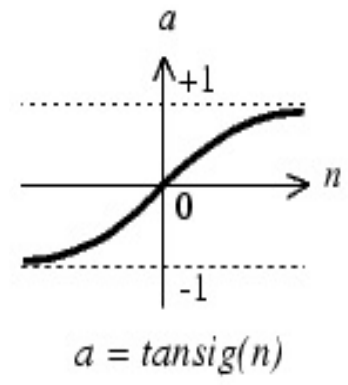

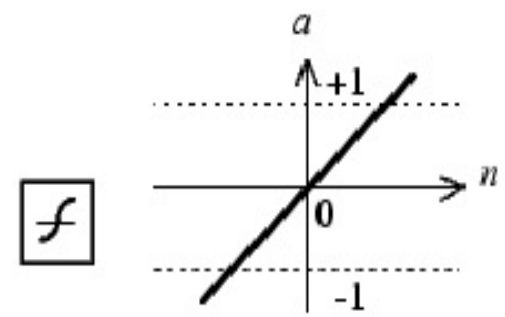

$a=\operatorname{purelin}(n)$

\section{Author's biography}

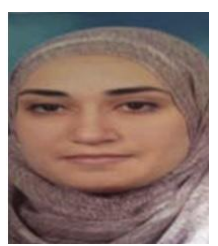

Dr. Rasha Aly Mohamed was born in Egypt in 1978. Dr. Rasha received the B. Sc. degree in Physics and Chemistry, the M.Sc. degree in Fluid Dynamics and Ph.D. degree in Hydromagnetic and Hydrodynamic stability from Faculty of Education Ain Shams University, in 1999, 2006 and 2010, respectively. Dr. Rasha is currently a lecturer at the Department of Physics, Faculty of Education, Ain Shams University. Her research interests are Fluid Mechanics, Nanofluids, Artificial Intelligence, Application of Artificial Neural Network Techniques in Physics.

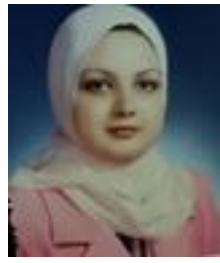

Dr. Doaa Mahmoud Habashy

I was born in Egypt 1980. I am a researcher in school of Artificial Intelligence. I received the B. Sc. degree in Physics and Chemistry, the M.Sc. degree in Theoretical Physics and Ph.D. degree in Artificial Neural Network from Faculty of Education, Ain Shams University, in 2001, 2007 and 2011, respectively. I am a lecturer at the Department of Physics, Faculty of Education, Ain Shams University. My main areas of research interest are Artificial Intelligence, Neural Network Model and its application in Physics for simulation and prediction. 